\title{
Influence of cultural practices on breast cancer risks, stage at presentation and outcome in a multi-ethnic developing country (Review)
}

\author{
NORLIA ABDULLAH ${ }^{1}$ and NORAZLINA MOHAMED ${ }^{2}$ \\ Departments of ${ }^{1}$ Surgery and ${ }^{2}$ Pharmacology, University Kebangsaan Malaysia \\ Medical Centre, 56000 Kuala Lumpur, Malaysia
}

Received March 17, 2021; Accepted July 23, 2021

DOI: $10.3892 / \mathrm{ol} .2021 .13067$

\begin{abstract}
Malaysia is a developing country made up of three main ethnicities: Malay, Chinese and Indian. There are significant ethnic differences with regard to the type of daily food and cooking methods, contraception, breast-feeding preferences, confinement period and care, postmenopausal intake and influence of the traditional healer. Breast cancer is the most common cancer among Malaysian women across all three ethnicities. However, the National Cancer Registry and local medical centres have documented ethnic differences in breast cancer risk (Chinese, 40.7 per 100,000; Indian, 38.1 per 100,000; Malay, 31.5 per 100,000), peak age (youngest in the Malays), stage at presentation (largest percentage at advanced stage among the Malays) and survival (poorest survival rate among the Malays). The Malays have several practices that are protective against breast cancer compared with the Chinese. However, the Malays have strong beliefs in the traditional healer, which contribute to the delay in getting treatment, causing a poor outcome and a low survival rate. The highest BRCA1 and 2 genetic mutation incidence is amongst the Chinese, but the Malays have the largest triple-negative breast cancer rates. These factors may also contribute to the statistical breast cancer data.
\end{abstract}

\section{Contents}

1. Introduction

2. Dietary habits

3. Confinement diet

Correspondence to: Professor Norlia Abdullah, Department of Surgery, University Kebangsaan Malaysia Medical Centre, Jalan Yaacob Latif, Bandar Tun Razak, Cheras, 56000 Kuala Lumpur, Malaysia

E-mail:norlia@ppukm.ukm.edu.my

Key words: developing, ethnic, culture, breast, cancer, risk, outcome, survival
4. Fertility rate
5. Breastfeeding
6. Postmenopausal diet
7. Traditional healer
8. Genetic mutations
9. Cumulative overall survival
10. Comparison between three ethnic groups
11. Conclusion

\section{Introduction}

Worldwide, breast cancer is the second most commonly diagnosed cancer when statistics for both sexes are combined. For women, breast cancer is the most commonly diagnosed cancer and the leading cause of mortality (1). In Asia, the most common cancer types in women are breast, lung, cervical, colorectal and stomach cancer. The mortality-to-incidence ratios are the highest in lung, liver and stomach cancer, and the lowest in colorectal, breast and prostate cancer (2). In 2012 , there were 639,824 cases of breast cancer recorded in Asian countries, with 228,926 deaths. Malaysia recorded 5,410 cases of breast cancer, with 2,572 deaths, in 2012 (3). Based on Malaysia's 2016 National Cancer Registry, a total of 21,634 cases of female breast cancer were diagnosed over a period of 4 years between 2012 and 2016 compared with 18,206 cases in the 2007-2011 report. Breast cancer is the most common cancer and has accounted for $34.1 \%$ of all cancer cases among women in Malaysia. The age-standardised rate was increased from 31.1 per 100,000 population in 2007-2011 to 34.1 between 2012 and 2016 (4).

Malaysia is a developing country made up of three main ethnicities: Malay, Chinese and Indian. Multi-ethnicity in Malaysia started after the establishment of the Straits Settlements in Penang, Malacca and Singapore, and later on, the acquisition of the Malay territories by the British. These British colonizers brought in a number of labourers from China and India to work on the land (5). The Chinese migrants were placed to work in tin mines, whilst the Indian population laboured in the rubber plantations.

With regard to the breast cancer incidence rate among the three major ethnic groups, the incidence is highest among 
the Chinese (40.7 per 100,000 individuals) followed by the Indians (38.1 per 100,000 individuals) and the Malays (31.5 per 100,000 individuals). The overall lifetime risk is 1 in 22 for the Chinese, 1 in 23 for the Indians and 1 in 30 for the Malays (4). The Malays have been observed to be significantly younger at the time of cancer presentation (average, 50 years old) compared with the Chinese (average, 57 years old) and Indians (average 56 years old). The Malays also have a more advanced stage at diagnosis compared with the other two ethnic groups (6). The Malay ethnicity was observed to be a poor prognostic factor in breast cancer, conferring 1.5 times the risk of death compared with the Chinese ethnicity (7). Similarly, it was noted that the Malays had a lower survival rate of $39.7 \%$ compared with $48.2 \%$ in the Chinese and $47.2 \%$ in the Indians (8). These Malay women presented with the more advanced stages compared with the women of the other two ethnicities, and had the worst survival rate $(9,10)$. Singapore, which is a multi-ethnic country similar to Malaysia, also reported a similar breast cancer incidence rate that was higher among Chinese women compared with that among the Malays and Indians (11). Table I shows the statistics of breast cancer among the different ethnic groups.

Although there has been ethnic integration, and the occurrence of marriages between ethnicities, each group has largely retained its own unique culture and way of life. In Malaysia, the statistical data combines the Malays with the smaller indigenous groups to form the Bumiputera group. The Malays (Bumiputera) now make up $69.6 \%$ of the population, the Chinese $22.6 \%$ and the Indians $6.8 \%$, with the remaining percentage being constituted from the other ethnic minorities. The total population now stands at 32.6 million people (12)

According to a review of the literature, to the best of our knowledge, there has been only one paper discussing the possible causes or correlation between the lifestyle and culture of the three ethnicities in Malaysia and breast cancer risk (13). However, this paper lacks references for a number of the points that were raised. A large part of this paper discussed the general lifestyles that had led to Malaysian women developing cancer as a whole, but did not compare the practices between the different ethnicities, as the title had suggested.

The present review comprehensively analyses different cultural practices and how they may have affected the risk, stage at presentation and outcome of women with breast cancer in Malaysia, a multi-ethnic developing country. The significant ethnic differences appear to be in the type of daily food and cooking methods, contraception, fertility rates, breast-feeding practices, confinement period and care, postmenopausal intake and influence of the traditional healer, which are all discussed.

\section{Dietary habits}

As in most cases, dietary practices play a big role with regard to health. The three ethnic races in Malaysia have their preferences in food preparation. The Malays and the Indians use a lot of turmeric or curcumin in their routine cooking, consisting of curries and other spicy gravies. Curcumin is a polyphenol from the plant Curcuma longa. Although not a phyto-oestrogen, it has been shown to inhibit the proliferation of various breast cancer cell lines and also to induce the apoptosis of breast cancer cells (14). Curcumin has also been found to minimise the risk of metastases in breast cancer by downregulating the inflammatory cytokines $\mathrm{C}-\mathrm{X}-\mathrm{C}$ motif chemokine ligand 1 and 2 via nuclear factor- $\kappa \mathrm{B}$, an inflammation- and cell survival-related transcription factor (15).

The typical Chinese diet does not include turmeric. Instead, a lot of soya (soy) products, consisting of soya sauce, bean curd and soya-bean drink, are used. Soya beans fall in the isoflavones category of phyto-oestrogens. In a dose-response meta-analysis report, each increment of $10 \mathrm{mg} / \mathrm{day}$ soy isoflavone was associated with a $3 \%$ decreased breast cancer risk (16). Phyto-oestrogens are very weak mimickers of natural oestrogens, with an affinity for oestrogen receptors of 1,000-10,000 times lower than oestradiol (17). There are two types of oestrogen receptors (ERs), ER- $\alpha$ and ER- $\beta$. Stimulation of ER- $\alpha$ causes an increase in tumour growth, but stimulation of ER- $\beta$ causes tumour regression. Oestradiol has equal affinity for both types of ERs. Tamoxifen has double the affinity for ER- $\beta$ compared with that for ER- $\alpha$. However, phyto-oestrogens have five times greater affinity for ER- $\beta$ compared with that for ER- $\alpha$ (18). A bi-phasic behaviour of isoflavones has also been observed in vitro, whereby a low dose stimulated the growth of MCF-7 cells (ER-positive breast cancer cell line), but not MDA-MB cells (ER-negative breast cancer cell line). At high doses, isoflavones inhibit the growth of both ER-positive and -negative cell lines $(19,20)$. Another important Chinese cooking ingredient is sesame, which is consumed as seeds and as sesame oil (21). Sesame seeds contain a lignan, which is also a type of phyto-oestrogen. However, its chemical compound, enterolactone, is metabolized in the gut and may have limited effects on humans (17).

In another study, a low dietary fibre intake was associated with higher risks of developing breast cancer (22). In a nutrient-wide association study, it was reported that a high intake of fibre and fruits was associated with a lower breast cancer risk (23). It was found that the total consumption of vegetables and fruits differ amongst the different ethnic groups in Malaysia. The Malays have the highest consumption, followed by the Chinese and the Indians (24), and this may influence breast cancer risk in these ethnic groups.

In Malaysia, alcohol consumption is significantly higher among males compared with females. Among the three ethnic groups, binge drinking was recorded to be highest in the Indians (54\%), followed by the Chinese at $39 \%$ and the Malays at $8 \%$ (25). The Malay women, who are Muslims, do not consume alcohol as it is forbidden in Islam. Some Chinese women consume alcohol on social occasions and some Indian women in the estates consume illicit alcohol (samsu) (26). Frequent and high consumption of alcohol are risk factors for breast cancer, as shown in a study among premenopausal women in Japan (27). Similarly, one report identified alcohol as one of the environmental factors related to cancer (28). Due to the differences in alcohol consumption among the ethnic groups, breast cancer risk and incidence may also differ.

\section{Confinement diet}

Across the three ethnicities, the confinement period is traditionally regarded important in order to protect the well-being 
Table I. Statistics of breast cancer and genetic mutations among the different ethnic groups in Malaysia.

\begin{tabular}{lcccr}
\hline Statistic & Malay & Chinese & Indian & (Refs.) \\
\hline Incidence (per 100,000) in a 5-year period & & & & $(4)$ \\
2007-2011 & 27.2 & 41.5 & 37.1 & \\
2012-2016 & 31.5 & 40.7 & 38.1 & $(4)$ \\
Overall lifetime risk & 1 in 30 & 1 in 22 & 1 in 23 & $(6)$ \\
Age at presentation, years & 50 & 57 & 56 & $(9)$ \\
& 46 & 51 & 53 & $(6)$ \\
Metastatic disease at presentation, $\%$ & 14.2 & 9.2 & 11.9 & $(9)$ \\
& 16 & 9 & 4 & $(9)$ \\
Median tumour size at diagnosis, mm & 35 & 25 & 52.5 & $(9)$ \\
Oestrogen receptor-positive tumours, $\%$ & 52.5 & 58.1 & 47.5 & $(9)$ \\
Oestrogen receptor-negative tumours, $\%$ & 47.5 & 41.9 & 43.9 & $(9)$ \\
High-grade tumours, \% & 44.7 & 39.4 & 47.2 & $(8)$ \\
Malaysian 5-year survival rate, $\%$ & 39.7 & 48.2 & 6.45 & $(10)$ \\
Malaysian average survival time, years & 6.41 & 7.10 & 68 & $(9)$ \\
Malaysian-Singapore 5-year survival rate, $\%$ & 58.5 & 75.8 & 11.8 & $(65)$ \\
BRCA1 and 2 mutations, $\%$ & 23.5 & 63.1 & & \\
\hline
\end{tabular}

of the woman, as it allows the body to recuperate and recover from childbirth. At the time, certain dietary practices are observed. 'Hot foods' are recommended. 'Hot foods' refer to spicy food, with the effect of making the one eating it sweat easily. The Malay confinement period lasts 44 days in which the new mother would be required to wear a special corset (bengkung) (29). Firstly, two large rectangle pieces of cloth are sewn together with a central compartment filled with spices; this is placed over the front of the belly. Next, a long plain piece of cloth is wrapped snugly around the body, over the spice-filled piece, starting from the upper down to the lower abdomen. The new mother would undergo whole body massage daily. Warm compression from heated stones would be placed on the abdominal wall for several minutes at a time, daily, over 3-7 days; this is similar to the application of a hot water bottle. The confinement diet consists of not only young tubers of turmeric, but also its young shoots. Other foods consist of the snake-head fish (ikan haruan), anchovies, meat, ginger, black pepper and a herb locally known as Kacip Fatimah [Labisia pumila $(L P)]$. This herb has been found to have cytotoxic activity against the MCF-7 breast cancer cell line $(30,31)$, prostate cancer cell lines $(32,33)$ and melanoma cells (34). It has also been found to have anti-fungal and anti-inflammatory properties (30), including bronchodilatory properties (35).

The confinement period for Chinese women is a month. The confinement diet consists of large amounts of ginger and sesame, as well as special brews in the form of rice wine in which chicken and pork trotters had been simmered. Some women are also given additional drinks such as Dom Pérignon, a French wine, which is highly regarded by the Chinese to be good for women during confinement (21).

During the confinement period, Chinese women are also given Ginseng (Panax ginseng) and Dong Quai or Tong Kuei (Angelica sinensis). Traditionally known as 'female ginseng', Dong Quai is often given to women at other times too. Amongst its indicated properties are the improvement of fertility and libido, and the treatment of dysmenorrhoea and premenstrual syndrome (21). Amato et al (36) showed that, in vitro, Dong Quai and Ginseng increased breast cancer cell line multiplication by 16 and 27 times, respectively. However, recent studies $(37,38)$ have shown conflicting findings. Dong Quai did not exert significant stimulatory effects on breast cancer in both an in vivo breast tumour xenograft-bearing nude mouse model and in an in vitro human breast cancer cell line. However, precaution is required if Dong Quai is to be used in oestrogen receptor-positive breast cancer patients due to its ability to induce oestrogen receptor- $\alpha$ expression and its tumorigenic potential via promotion of cancer stem cell activity in oestrogen receptor-positive breast cancer $(39,40)$. Ginseng has also been shown to inhibit the proliferation of breast cancer cell lines in a time- and dose-dependent manner by activating the apoptotic pathway (41).

Similar to the Chinese, the Indian women undergo a confinement of 30 days. However, their diet is very different from that of Chinese women. Indian women avoid 'cooling foods' such as cucumber, murungai (Moringa oleifera) fruits and grapes, but are encouraged to consume more spices such as black pepper, cardamon, aniseed, turmeric and ginger (42). In a study conducted in Singapore, Indian women were also observed to increase their consumption of garlic (43). A high consumption of garlic has been shown to have an inverse association with breast cancer, as reported in a study conducted among women aged 39-70 years in Puerto Rico (44).

\section{Fertility rate}

The fertility rates of the three ethnicities differ, with the highest amongst Malay women and the lowest among Chinese women (12). There is a close association between breast cancer and parity, whereby increased parity or fertility lessens breast cancer risk (28).

In 2014, it was found that 52\% of Malaysian women practiced family planning consisting of both non-modern and modern 
methods. The most favoured modern contraception was the oral contraceptive pill (OCP) at $13.2 \%$ usage (45). Contraceptive practices also differed between the ethnicities, with the pill being used the most by Chinese women (45.6\%), followed by the Indian (32.2\%) and Malay (28.2\%) women (46). Use of the OCP has been shown to increase breast cancer risk (28).

\section{Breastfeeding}

Breastfeeding is beneficial to both the mother and the child. For the mother, there is an association with a decreased breast cancer risk if the baby is breastfed for $>6$ months (28). Local data have shown that a higher percentage of Malays tend to breastfeed longer compared with the percentage of Chinese (47). In one study, it was determined that Chinese women who were working, from a high income family and with male infants were less likely to breastfeed their baby (48). In a study that analysed a group of 682 women (Malays, 60.9\%; Chinese, 18.7\%; and Indians, 16\%), it was found that exclusive breastfeeding for the first 6 months was practised by $52.5 \%$ of the Malays, $15.6 \%$ of the Chinese and $35.8 \%$ of the Indians (49).

\section{Postmenopausal diet}

Similar to during the confinement period, LP is also commonly taken by Malay women postmenopause. The menopause is associated with several symptoms and mental health changes (vasomotor symptoms and cognitive function), as well as changes in physiological systems and functions (cardiovascular and bone health) (50). In rats who were given LP and oestrogen, the collagen fibres that held the adipocytes together became fragmented causing lipolysis. This showed that there is a possible role for LP in preventing postmenopausal obesity (51). Additionally, a study by Fazliana et al (52) showed that the plant caused an increase in the production of leptin, leading to weight loss and improvement in insulin sensitivity. Nadia et al (53) demonstrated the anti-oxidative role of LP, and Abdul Kadir et al (54) found it to lower serum triglyceride levels. High triglyceride levels have been shown to be associated with coronary heart disease in postmenopausal women $(55,56)$.

A study comparing LP with premarin, one of the medications used for hormone replacement therapy, showed that LP did not prevent the loss of bone mass (57). However, another study in animal models showed it to be comparable to premarin in preventing osteoporotic fractures in oestrogen-deficient states (58). A pilot study on women administered LP extracts demonstrated no increase in mammographic density (59). This is important, as an increase in mammographic density would make interpretation more difficult and has been shown to increase breast cancer risk $(60,61)$.

Just like in Chinese women during the confinement period, Chinese postmenopausal women take Dong Quai to treat vasomotor symptoms (21). As shown by Amato et al (36), these menopausal women now have an added risk of developing breast cancer due to this consumption.

\section{Traditional healer}

According to the Malay culture, the traditional healer or medicine man, known as a 'bomoh', is much respected in society.
This is especially so among the rural population (62). Often, the services of the healer is sought after for numerous illnesses in both children and adults. These include physical illnesses, spiritual illnesses and those believed to be related to sorcery or black-magic. Even family related issues like infidelity, separation, divorce or the search for a life partner often involve seeking the advice of the healer.

In Malaysia, the highest users of traditional and complementary treatment are the Sabah Natives, followed by the Malays (63). Among all patients with breast cancer, there are several reasons for seeking traditional healers, including recommendations from family members and friends, sanction from family, perceived benefit and compatibility, healer credibility, and reservation towards Western medicine and system delays (64).

For physical lesions, one of the common taboos conveyed by these healers is contact of the affected body part with metal objects. Those who follow these orders would not come to hospital, as often a biopsy would need to be taken, which would involve the use of metal needles. When the treatment from a particular healer did not work or the illness did not go away, a second or third bomoh would be consulted. Only after failing these treatments, which could lead to a delay of 6 to 12 months, would these women present themselves to a hospital. This accounts for the late diagnosis at stages 3 or 4 for Malay women with breast cancer. As expected, these women with more advanced diseases have poorer outcomes. Among the three ethnicities, the Malay women are the worst affected in this regard (8-10).

\section{Genetic mutations}

Genetic research performed by Thirthagiri et al (65) discovered that Chinese women had the highest incidence of BRCA1 and 2 mutations at $63.1 \%$, followed by Malay women at $23.1 \%$ and Indian women at $11.8 \%$. Among the Chinese women, there was an equal proportion of BRCA1 and 2 mutations. There was more BRCA2 mutations among the Malays. These mutations led to early onset breast cancer (age $\leq 40$ years). A total of 27 deleterious mutations were detected (14 in BRCA1 and 13 in BRCA2), and 47 variants of uncertain clinical significance were identified (16 in BRCA1 and 31 in BRCA2). This study may significantly contribute to the current statistical evidence on incidence of breast cancer by ethnicity.

\section{Cumulative overall survival}

The cumulative overall survival of Malaysian and Singaporean women (9) was demonstrated in a full model adjusted for socio-demographic factors, tumour characteristics and treatment (Fig. 1). The findings showed that the cumulative overall survival rate was lowest for Malay women. This data was also supported by results from other previous studies $(8,10)$.

\section{Comparison between three ethnic groups}

Chinese women who have the lowest fertility rate, highest OCP use, poorest breast feeding practices and highest alcohol intake are associated with increased breast cancer risks. Soya seems to be associated with decreased cellular proliferation in vitro. However, a diet rich in soya alone, as one beneficial factor, would not be able to overcome all the other negative 
Table II. Cultural practices of the three major ethnic groups in Malaysia and breast cancer risks.

A, Dietary habits

Ethnicity Practice $\quad$ Breast cancer risk

Malay Turmeric/curcumin consumption

High consumption of vegetables and fruits

Chinese Soy product consumption

Alcohol consumption

Indian Turmeric/curcumin consumption

Alcohol consumption
Reduced risk: Curcumin inhibits proliferation and induces apoptosis of breast cancer cell lines (14)

Reduced risk: High dietary fibre reduces breast cancer risk in a study of Malaysians compared with controls (22) Women, aged 25 to 70 years, followed-up for 15 years, in the European Prospective Investigation into Cancer and Nutrition Study showed that high fibre intake reduced breast cancer risk (23)

Reduced risk: A meta-analysis of Chinese women (aged 30-79 years) followed up for 10 years and other studies in Asia and Western countries found that an increase in soy intake reduced breast cancer risk (16)

Increased risk: Alcohol consumption is a risk factor for breast cancer in premenopausal women (25)

Reduced risk: As aforementioned (14)

Increased risk: As aforementioned (25)

B, Confinement diet

\begin{tabular}{|c|c|c|}
\hline Ethnicity & Practice & Breast cancer risk \\
\hline \multirow[t]{2}{*}{ Malay } & Turmeric/curcumin consumption & Reduced risk: As aforementioned (14) \\
\hline & Kacip Fatimah (Labisia pumila) consumption & $\begin{array}{l}\text { Reduced risk: Cytotoxic activity against the MCF-7 breast } \\
\text { cancer cell line }(30,31)\end{array}$ \\
\hline \multirow[t]{2}{*}{ Chinese } & Alcohol consumption & Increased risk: As aforementioned (25) \\
\hline & Ginseng and Dong Quai (Angelica sinensis) consumption & $\begin{array}{l}\text { Conflicting reports: Recent studies showed that Dong Quai } \\
\text { did not induce breast cancer but caution use in oestrogen } \\
\text { receptor-positive breast cancer patients, while ginseng } \\
\text { inhibits growth of breast cancer cell lines }(37,38)\end{array}$ \\
\hline Indian & Turmeric/curcumin & Reduced risk: As aforementioned (14) \\
\hline
\end{tabular}

C, Fertility rate

Ethnicity Practice

Malay Highest parity rate, lowest usage of OCP

Chinese Lowest parity rate, highest usage of OCP

Indian Parity and usage of OCP ranking between that of the

Malays and the Chinese

\section{Breast cancer risk}

Reduced risk: Increased parity lessens breast cancer risks (28)

Increased risk: Use of OCP increase breast cancer risk (28)

Medium risk

D, Breastfeeding

Ethnicity Practice

Malay Most practiced

Chinese Least practiced

Indian In between the Malays \& the Chinese
Breast cancer risk

Reduced risk: Decrease breast cancer risk if breastfeeding for $>6$ months (28)

Increased risk: No breast feeding protective effect against breast cancer (27)

Reduced risk: Decrease breast cancer risk if breastfeeding for $>6$ months (28) 
Table II. Continued.

E, Postmenopausal diet

\begin{tabular}{lll}
\hline Ethnicity & \multicolumn{1}{c}{ Practice } & \multicolumn{1}{c}{ Breast cancer risk } \\
\hline Malay & Kacip Fatimah (Labisia pumila) consumption & Reduced risk: As aforementioned (30,31) \\
Chinese & Dong Quai (Angelica sinensis) consumption & Conflicting reports: As aforementioned (37) \\
Indian & Data not available & Data not available \\
\hline
\end{tabular}

F, Traditional healer

\begin{tabular}{|c|c|c|}
\hline Ethnicity & Practice & Breast cancer risk \\
\hline Malay & Strong belief & Increased risk: These women had the worst outcome (8-10) \\
\hline Chinese & No strong belief & No increased risk \\
\hline Indian & No strong belief & No increased risk \\
\hline
\end{tabular}

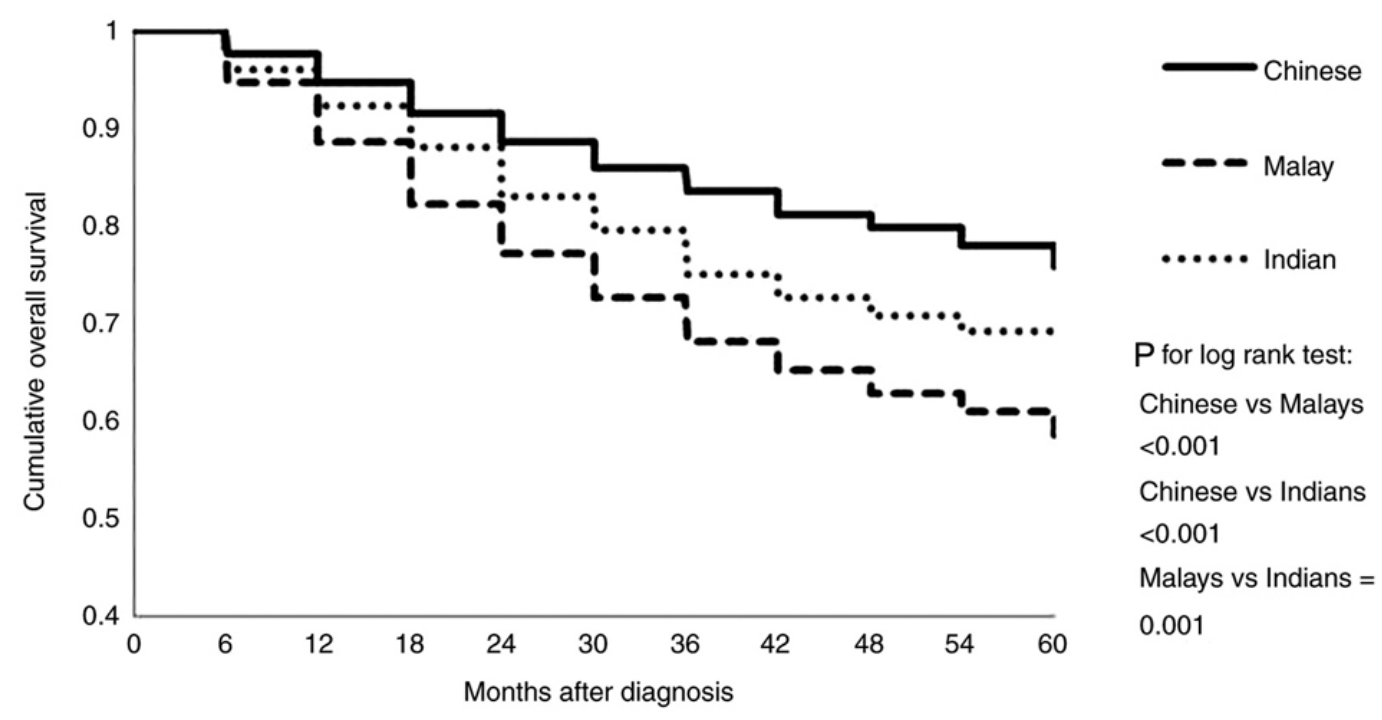

Figure 1. Cumulative overall survival by ethnicity in 5,264 South East Asian women with breast cancer. From Nirmala Boo-pathy (9), doi: 10.1371/journal. pone.0030995.g001.

lifestyle practices. With the added factor of having the highest incidence of BRCA1 and 2 genetic mutations amongst the three ethnicities, it is not unexpected that Chinese women have the highest risk of breast cancer.

In comparison, Malay women have the highest fertility rate, lowest OCP usage, best breast feeding practices, no alcohol consumption and the intake of a herb (Kacip Fatimah) with in vitro cytotoxic properties. All of these are in favour of lowering breast cancer risks. The setback among this group is a strong belief in the traditional healer, which causes late presentation to hospitals and poor survival outcomes.

The practices observed by Indian women come between those practiced by the Chinese and the Malays, which put them second highest in terms of breast cancer risk. Table II summarizes the differences in cultural practices among the three ethnic groups and the influence on breast cancer risk.

A large part of the aforementioned herbal research showed findings from in vitro studies and animal models, with limited studies in humans. Although this is a commendable start, further clinical trials need to be completed in order to produce more robust data to facilitate the use of such herbs in the clinical setting. From the current data, LP appears a safer option than hormone replacement therapy, which is associated with elevated breast cancer risks according to the Women's Health Initiative study, plus increased risks of stroke and thromboembolic diseases (66).

The peak age of breast cancer in Malay women is lower compared with that in Chinese and Indian women $(6,9)$. This may be related to the different cancer subtypes among the ethnic groups. The luminal A subtype occurs significantly more frequently in the Chinese than in the Malays. However, the percentage of triple-negative subtype cases is significantly higher in the Malays than in the Chinese (67). Triple-negative breast cancer has been associated with a younger age at the time of diagnosis and a more advanced disease stage (68). However, when Asians as a whole are considered, the peak 
age of breast cancer incidence is between 40 and 50 years old, as opposed to between 60 and 70 years old in Western countries (69). Biological, genetic and the environmental factors may contribute to these differences.

\section{Conclusion}

Based on the data presented, the three ethnicities have distinct cultural practices that may influence breast cancer occurrence. The lowest incidence of breast cancer in the Malays may be attributable to their lifestyle and cultural practices. However, the Malays present with the disease at an advanced stage and have a low survival rate. It is hoped that the three ethnicities will learn from each other and adjust their cultural practices. This would mean continuing the beneficial praticises and abandoning the detrimental ones. This is a challenging task and may take a longer time, as often traditional changes occur more easily with a newer generation. Some individuals may have sensitive sentiments attached to their cultural practices and will oppose changes. The government and non-government organisations would need to work together to educate the public to increase their breast cancer awareness and advocate the best lifestyle practices. This would be the best way forward in an attempt to decrease the incidence of breast cancer and improve the outcome at a national level as Malaysia strives forward to become a developed country in the future. Besides Malaysia, the aforementioned information may be beneficial to Asians worldwide who share a similar lifestyle and diet.

\section{Acknowledgements}

Not applicable.

\section{Funding}

Not applicable.

\section{Availability of data and materials}

Not applicable.

\section{Authors' contributions}

NA conceptualized the study and prepared the original and final drafts. NM reviewed and edited the article. All authors have read and approved the manuscript. Data authentication is not applicable.

\section{Ethics approval and consent to participate}

Not applicable.

\section{Patient consent for publication}

Not applicable.

\section{Competing interests}

The authors declare that they have no competing interests.

\section{References}

1. Bray F, Ferlay J, Soerjomataram I, Siegel RL, Torre LA and Jemal A: Global cancer statistics 2018. GLOBOCAN estimates of incidence and mortality worldwide for 36 cancers in 185 countries. CA Cancer J Clin 68: 394-424, 2018.

2. Ng CJ, Teo CH, Abdullah N, Tan WP and Tan HM: Relationships between cancer pattern, country income and geographical region in Asia. BMC Cancer 15: 613, 2015.

3. Ghoncheh M, Momenimovahed Z and Salehiniya H: Epidemiology, incidence and mortality of breast cancer in Asia. Asian Pac J Cancer Prev 17 (S3): 47-52, 2016.

4. Azizah AM, Hashimah B, Nirmal K, Siti Zubaidah AR, Puteri NA, Nabihah A, Sukumaran R, Balqis B, Nadia SMR, Sharifah SSS, et al: Malaysian National Cancer Registry Report 2012-2016. National Cancer Institute, Ministry of Health, Putrajaya, Malaysia, 2019. https://www.moh.gov.my/moh/resources/Penerbitan/ Laporan/Umum/2012-2016\%20(MNCRR)/MNCR_2012-2016 FINAL (PUBLISHED_2019).pdf. Accessed September 17, $20 \overline{2} 1$.

5. Razaleigh MK, Abdul Ghafar D, Salasiah Hanin H, Fariza MS, Badlihisham MN, Muhammad Faisal A, Siti Rugayah T, Zainab I, Ideris E, Anuar P, et al: The history of ethnic relationship in Malaysia. Adv in Nat Appl Sci 6: 504-510, 2012.

6. Deniel A, Hakim NA, Md Nordin NA, Tg Abu Bakar Sidik TMI, Subramaniam S, Kamaruzaman ND and Ros Suzana AB: Ethnic differences in presentation of breastcancer patients treated in Hospital Kuala Lumpur, Malaysia. Ann Oncol 26 (Suppl 9): ix16-ix33, 2015.

7. Taib NA, Akmal M, Mohamed I and Yip CH: Improvement in survival of breast cancer patients-trends over two time periods in a single institution in an Asia Pacific country, Malaysia. Asian Pac J Cancer Prev 12: 345-349, 2011.

8. Ibrahim NI, Dahlui M, Aina EN and Al-Sadat N: Who are the breast cancer survivors in Malaysia? Asian Pac J Cancer Prev 13: 2213-2218, 2012.

9. Bhoo-Pathy N, Hartman M, Yip CH, Saxena N, Taib NA, Lim SE, Iau P, Adami HO, Bulgiba AM, Lee SC and Verkooijen HM: Ethnic differences in survival after breast cancer in South East Asia. PLoS One 7: e30995, 2012.

10. Al-Naggar RA, Isa ZM, Shah SA, Nor MI, Chen R, Ismail F and Al-Dubai SA: Eight year survival among breast cancer Malaysian women in University Kebangsaan Malaysia medical centre. Asian Pac J Cancer Prev 10: 1075-1078, 2009.

11. National Registry of Diseases Office: Singapore Cancer Registry Annual Registry Report Trends in Cancer Incidence in Singapore 2010-2014. (NRDO), Singapore, 2015.

12. Department of Statistics Malaysia: Current Population Estimates, Malaysia, 2021. https://www.dosm.gov.my/v1/index. php? $\mathrm{r}=$ column/cthemeByCat\&cat=155\&bul_id=ZjJOSnpJR21s QWVUcUp6ODRudm5JZz09\&menu_id=L0pheU43NWJwRW VSZklWdzQ4TlhUUT09. Accessed September 19. 2021.

13. Shadiya MSB, Gogilawani W, Akbariah MM and Saidatul S: Causes of breast cancer: Comparison between the three races in Malaysia. J Health Sci 2: 19-29, 2012.

14. Hu S, Xu Y, Meng L, Huang L and Sun H: Curcumin inhibits proliferation and promotes apoptosis of breast cancer cells. Exp Ther Med 16: 1266-1272, 2018.

15. Bachmeier BE, Mohrenz IV, Mirisola V, Schleifer E, Romeo F, Hohneke C, Jochum M, Nerlich AG and Pfeffer U: Curcumin downregulates the inflammatory cytokines CXCL1 and -2 in breast cancer cells via NFkappaB. Carcinogenesis 29: 779-789, 2008.

16. Wei Y, Lv J, Guo Y, Bian Z, Gao M, Du H, Yang L, Chen Y, Zhang X, Wang T, et al: Soy intake and breast cancer risk: A prospective study of 300,000 Chinese women and a dose-response meta-analysis. Eur J Epidemiol 35: 567-578, 2020.

17. Rice Sand WhiteheadSA:Phytoestrogens and breastcancer-promoters or protectors? Endocr Relat Cancer 13: 995-1015, 2006.

18. Kuiper GG, Lemmen JG, Carlsson B, Corton JC, Safe SH, van der Saag PT, van der Burg B and Gustafsson JA: Interaction of estrogenic chemicals and phytoestrogens with estrogen receptor beta. Endocrinology 1399: 4252-4263, 1998.

19. Nakagawa H, Yamamoto D, Kiyozuka Y, Tsuta K, Uemura Y, Hioki K, Tsutsui Y and Tsubura A: Effects of genistein and synergistic action in combination with eicosapentaenoic acid on the growth of breast cancer cell lines. J Cancer Res Clin Oncol 126: 448-454, 2000.

20. Dampier K, Hudson EA, Howells LM, Manson MM, Walker RA and Gescher A: Differences between human breast cell lines in susceptibility towards growth inhibition by genistein. $\mathrm{Br}$ J Cancer 85: 618-624, 2001. 
21. Poh BK, Wong YP and Norimah AK: Postpartum dietary intake and food taboos among chinese women attending maternal and child health clinics and maternity hospital, Kuala Lumpur. Mal J Nutr 11: 1-21, 2005.

22. Suzana S Jr, Azhar Y and Fatimah A: Association between dietary fibre and cancer: A case-control study in Malaysia. Malays J Nutr 10: 173-182, 2004.

23. Heath AK, Muller DC, van den Brandt PA, Papadimitriou N, Critselis E, Gunter M, Vineis P, Weiderpass E, Fagherazzi G, Boeing H, et al: Nutrient-wide association study of 92 foods and nutrients and breast cancer risk. Breast Cancer Res 22: 5 , 2020.

24. Nurul Izzah A, Aminah A, Md Pauzi A, Lee YH, Wan Rozita WM and Siti Fatimah D: Patterns of fruits and vegetable consumption among adults of different ethnics in Selangor, Malaysia. Int Food Res J 19: 1095-1107, 2012.

25. Mutalip MH, Kamarudin RB, Manickam M, Abd Hamid HA and Saari RB: Alcohol consumption and risky drinking patterns in Malaysia: Findings from NHMS 2011. Alcohol Alcohol 49: 593-599, 2014

26. Asunta M: The alcohol problem in Malaysia: The Globe. GAPA Bangkok consultation: Alcohol in Asia. Issues: 3- 4. The Global Alcohol Policy Alliance, London, 2001.

27. Iwase M, Matsuo K, Koyanagi YNY, Ito H, Tamakoshi A Wang C, Utada M, Ozasa K, Sugawara Y, Tsuji I, et al: Alcohol consumption and breast cancer risk in Japan: A pooled analysis of eight population-based cohort studies. Int J Cancer 148 2736-2747, 2021

28. Parkin DM, Boyd L and Walker LC: 16. The fraction of cancer attributable to lifestyle and environmental factors in the UK in 2010. Br J Cancer 105 (Suppl 2): S77-S81, 2011.

29. Shariffah SSJ: Beliefs and practices surrounding postpartum period among Malay women. Proc Social Sci Res: 49-417, 2014.

30. Karimi E, Jaafar HZ and Ahmad S: Antifungal, anti-inflammatory and cytotoxicity activities of three varieties of Labisia pumila benth: From microwave obtained extracts. BMC Complement Altern Med 13: 20, 2013.

31. Mainasara MM, Abu Bakar MF and Linatoc AC: Malaysian medicinal plants' potential for breast cancer therapy. Asian J Pharm Clin Res 11: 101-117, 2018.

32. Jamaludin N, Hasham R, Ware I, Sarmidi MR and Abd Aziz R: Antiproliferative properties of Aqueous Labisia Pumila extract on prostate cancer cell lines. J Teknologi 77: 61-66, 2015.

33. Shenouda NS, Zhou C, Browning JD, Ansell PJ, Sakla MS, Lubahn DB and Macdonald RS: Phytoestrogens in common herbs regulate prostate cancer cell growth in vitro. Nutr Cancer 49: 200-208, 2004

34. Lope Pihie AH, Zakaria ZA and Othman F: Antiproliferative and proapoptotic effects of Labisia pumila ethanol extract and its active fraction in human melanoma HM3KO cells. Evid Based Complement Alternat Med 2012: 123470, 2012.

35. Patrick NO and Sophia OE: In vivo and in vitro anti-asthmatic effects of dichloromethane crude extract from the leaves of Labisia pumila. Global J Pharmacol 6: 126-130, 2012

36. Amato P, Christophe S and Mellon PL: Estrogenic activity of herbs commonly used as remedies for menopausal symptoms. Menopause 9: 145-150, 2002.

37. Chen JY, Wang YH, Hidajah AC and Li CY: A population-based case-control study on the association of Angelica sinensis exposure with risk of breast cancer. J Tradit Complement Med 10: 454-459, 2019.

38. Zhou WJ, Wang S, Hu Z, Zhou ZY and Song CJ: Angelica sinensis polysaccharides promotes apoptosis in human breast cancer cells via CREB-regulated caspase-3 activation. Biochem Biophys Res Commun 467: 562-569, 2015.

39. Zhu H, You J, Wen Y, Jia L, Gao F, Ganeson K and Chen J: Tumorigenic risk of Angelica sinensis on ER-positive breast cancer growth through ER-induced stemness in vitro and in vivo. J Ethnopharmacol 13: 114415, 2021.

40. Yue GG, Wong LS, Leung HW, Gao S, Tsang JY, Lin ZX, Law BK, Tse GM and Lau CB: Is danggui safe to be taken by breast cancer patients?-A skepticism finally answered by comprehensive preclinical evidence. Front Pharmacol 10: 706, 2019.

41. Al Shabanah OA, Alotaibi MR, Al Rejaie SS, Alhoshani AR, Almutairi MM, Alshammari MA and Hafez MM: Inhibitory effect of ginseng on breast cancer cell line growth via up-regulation of cyclin dependent kinase inhibitor, p21 and p53. Asian Pac J Cancer Prev 17: 4965-4971, 2016.
42. Mohd Yusoff Z, Amat A, Naim D and Othman S: Postnatal care practices among the Malays, Chinese and Indians: A comparison. SHS Web of Conferences 45: 05002, 2018.

43. Chen LW, Low YL, Fok D, Han WM, Chong YS, Gluckman P, Godfrey K, Kwek K, Saw SM, Soh SE, et al: Dietary changes during pregnancy and the postpartum period in Singaporean Chinese, Malay and Indian women: The GUSTO birth cohort study. Public Health Nutr 17: 1930-1938, 2014.

44. Desai G, Schelske-Santos M, Nazario CM, Rosario-Rosado RV, Mansilla-Rivera I, Ramirez-Marrero F, Nie J, Myneni AA, Zhang ZF, Freudenheim JL and Mu L: Onion and garlic intake and breast cancer, a case-control study in puerto rico. Nutr Cancer 72: 791-800, 2020

45. Choudhry UK: Traditional practices of women from India: Pregnancy, childbirth and newborn care. J Obstet Gynecol Neonatal Nurs 26: 533-539, 1997.

46. National Population \& Family Development Board of Malaysia 2004. http://www.frham.org.my/pdf/publication/Country\%20 Profile\%20Final.pdf. Accessed March 28, 2020.

47. Ishak S, Adzan NA, Quan LK, Shafie MH, Rani NA and Ramli KG: Knowledge and beliefs about breastfeeding are not determinants for successful breastfeeding. Breastfeed Med 9: 308-312, 2014

48. Tan KL: Knowledge, attitude and practice on breastfeeding in Klang, Malaysia. Int Med J Malaysia 8, 2009.

49. Tan KL: Factors associated with exclusive breastfeeding among infants under six months of age in Peninsular Malaysia. Int Breastfeed J 6: 2, 2011.

50. El Khoudary SR, Greendale G, Crawford SL, Avis NE, Brooks MM, Thurston RC, Karvonen-Gutierrez C, Waetjen LE and Matthews K: The menopause transition and women's health at midlife: A progress report from the Study of Women's Health Across the Nation (SWAN). Menopause 26: 1213-1227, 2019.

51. Ayida AW, Wan Nazimoom WM, Farihah HS and Azian AL: Effect of ovariectomy Labisia pumila var alata treatment and estrogen replacement therapy morphology of adipose tissue in ovariectomized Sprague Dawley rats. J Med Biol Sci 12006.

52. Fazliana M, Wan Nazaimoon WM, Gu HF and Ostenson CG: Labisia pumila extract regulates body weight and adipokines in ovariectomized rats. Maturitas 62: 91-97, 2009.

53. Nadia ME, Nazrun AS, Norazlina M, Isa NM, Norliza M and Ima Nirwana S: The anti-inflammatory, phytoestrogenic, and antioxidative role of Labisia pumila in prevention of postmenopausal osteoporosis. Adv Pharmacol Sci 2012: 706905, 2012.

54. Abdul Kadir A, Nik Hazlina NH, Wan Mohammad WB, Mohd DM, Wan Mohammad WM, Hassan II, Shukor N, Kamaruddin NA and Wan Mohamud WN: The effect of Labisia pumila var alata on postmenopausal women: A pilot study. Evid Based Complement Alternat Med 2012: 216525, 2012.

55. Pardhe BD, Ghimire S, Shakya J, Pathak S, Shakya S, Bhetwal A, Khanal PR and Parajuli NP: Elevated cardiovascular risks among postmenopausal women: A community based case control study from Nepal. Biochem Res Int 2017: 3824903, 2017.

56. Masson W, Siniawski D, Lobo M, Molinero G and Huerín M: Association between triglyceride/HDL cholesterol ratio and carotid atherosclerosis in postmenopausal middle-aged women. Endocrinol Nutr 63: 327-332, 2016 (In English, Spanish).

57. Shuid AN, Ping LL, Muhammad N, Mohamed $\mathrm{N}$ and Soelaiman IN: The effects of Labisia pumila var. alata on bone markers and bone calcium in a rat model of post-menopausal osteoporosis. J Ethnopharmacol 133: 538-542, 2011.

58. Fathilah SN, Abdullah S, Mohamed N and Shuid AN: Labisia pumila prevents complications of osteoporosis by increasing bone strength in a rat model of postmenopausal osteoporosis. Evid Based Complement Alternat Med 2012: 948080 , 2012.

59. Keat TB, Nik Mahdi NM, Basheer LM and Nik Hussain NH: Effect of Kacip Fatimah (Labisia pumila) water extract on mammographic density-A pilot study. Malaysian J Med Sci Supplement 14: 51-51. 1p, 2007.

60. Yaghjyan L, Colditz GA, Collins LC, Schnitt SJ, Rosner B, Vachon $\mathrm{C}$ and Tamimi RM: Mammographic breast density and subsequent risk of breast cancer in postmenopausal women according to tumor characteristics. J Natl Cancer Inst 103: $1179-1189,2011$.

61. Hou XY, Niu HY, Huang XL and Gao Y: Correlation of breast ultrasound classifications with breast cancer in Chinese women. Ultrasound Med Biol 42: 2616-2621, 2016.

62. Ariff KM and Khoo SB: Cultural health beliefs in a rural family practice: A Malaysian perspective. Aust J Rural Health 14: 2-8, 2006. 
63. Salihah Y, Siti Aishah H and Wan Norhayati WO: Traditional and complementary treatments among Malay, Chinese and Indian chronic diseases: A systematic review. Mal J Med Health Sci 15 (Suppl 1): S178-S183, 2019.

64. Muhamad M, Merriam S and Suhami N: Why breast cancer patients seek traditional healers. Int J Breast Cancer 2012: 689168, 2012.

65. Thirthagiri E, Lee SY, Kang P, Lee DS, Toh GT, Selamat S, Yoon SY, Taib NA, Thong MK, Yip CH and Teo SH: Evaluation of BRCA1 and BRCA2 mutations and risk-prediction models in a typical Asian country (Malaysia) with a relatively low incidence of breast cancer. Breast Cancer Res 10: R59, 2008.

66. Anderson GL, Limacher M, Assaf AR, Bassford T, Beresford SA, Black H, Bonds D, Brunner R, Brzyski R, Caan B, et al: Effects of conjugated equine estrogen in postmenopausal women with hysterectomy: The women's health initiative randomized controlled trial. JAMA 291: 1701-1712, 2004.
67. Devi CR, Tang TS and Corbex M: Incidence and risk factors for breast cancer subtypes in three distinct South-East Asian ethnic groups: Chinese, Malay and natives of Sarawak, Malaysia. Int J Cancer 131: 2869-2877, 2012.

68. Boyle P: Triple-negative breast cancer: Epidemiological considerations and recommendations. Ann Oncol 23 (Suppl 6): vi7-vi12, 2012.

69. Leong SP, Shen ZZ, Liu TJ, Agarwal G, Tajima T, Paik NS, Sandelin K, Derossis A, Cody H and Foulkes WD: Is breast cancer the same disease in Asian and Western countries? World J Surg 34: 2308-2324, 2010.

(c) (i) (9) This work is licensed under a Creative Commons Attribution-NonCommercial-NoDerivatives 4.0 International (CC BY-NC-ND 4.0) License. 